\title{
Comparative study between Chinese and western music aesthetics and culture
}

\author{
Jie CHEN \\ Weifang University of Science and Technology \\ Shouguang,Weifang,Shandong, 262700 China
}

\begin{abstract}
The feature comparison between Chinese and western music aesthetics is a big topic. Comparative study is the basic principle of our methodology, that is, study and research of music aesthetics in China are premises of western music aesthetics and vice versa, and take the study of aesthetics of music history as a priority in order to obtain a methodology reference. This article attempts to study the main characteristic of Chinese and western music aesthetics from the cultural perspective, and understand the similarities and differences between Chinese and western music culture through the comparison. Papers in the premise of summarizing and comparing Chinese and western music aesthetics characteristics, cut to the Chinese and western music aesthetics in the "harmony", "artistic conception", "reasonable" and so on in the aesthetic category.
\end{abstract}

Keywords- music esthetics thought; Music culture; comparative study

\section{INTRODUCTION}

Culture is the sum of all the times and all thoughts in a society, which can vividly reflects its cultural characteristics. The development of western music aesthetics has experienced a long historical process. In the history, as an important part of the western philosophy and aesthetics thought system, it is connected with the western different historical period, religious, political, and various humanities thought system. Observe nearly ten thousand years of Chinese music practice carefully, Chinese music as well as the whole Chinese culture has a long history and goes back to ancient times.

In other words, the Chinese traditional music esthetics thought, was saturated with the breath of a culture from the start. It not only makes China closer to the art of traditional philosophy, more artistic temperament, but also is more important to make the traditional Chinese music esthetics thought norm deeply by traditional culture. There is also a lot of similarity between Chinese and western aesthetic culture. But in the category and the specific form of art activities, it shows considerable differences between Chinese and western. So far, very few people compare Chinese and western music culture, and our focus is neither Chinese nor the classification of thought in western music aesthetics, but through the comparison of music aesthetics features more indepth understand the cultural essence of Chinese traditional music, and help us to better establish the Chinese nation great cultural connotation, to better grasp the value orientation of national culture. From the development of western music, western and Chinese music have respectively formed its own characteristics. It is also because its own culture, its own historical background and different aesthetic in the very great degree. Because of various reasons, Chinese and western music are very different but there are still similarity. However, with the further development of the society and the advancement of global, music concerts gradually become the common language of the people to express emotion. It is in this age of flowers and the comparative study of Chinese and western music aesthetics is a very meaningful thing.

\section{CULTURAL COMPARISON BETWEEN CHINESE AND WESTERN MUSIC AESTHETICS}

\section{A. The similarities and differences between Chinese and western music structure}

From the structure of music language, the Chinese music language lay particular stress on psychological, slightly in the form. The notation in the form of the spectrum is various. The same spectrum could have different notation or playing method. The same tune can have different styles. Delimit phrase is free, and rhythm has flexibility. The performers can change randomly. Music syntax structure is open. Western music language form is rigorous, with clear topic sentences and harmony tonal music material logic relationship. Player performed strictly abide by the syntactic structure, and structure is fixed and closed. From the operation mode of music language, the Chinese traditional music is taught by mouth and heart. The formation of genres mainly is through the distinctive performances. Western traditional mode of operation is to explain the original music language, not beyond the work itself to shape character. Therefore, there is no apparent classification concept in the western as Chinese musical styles and genres. Chinese music is also not like western that Composer genres are established through notation of art concept. The origin of the harmonious idea between Chinese and western culture are related to music, but the west emphasizes the science of music, while China emphasizes the political function of music.

\section{B. Different feelings expressed in Chinese and western music}

Chinese music is gentle and harmonious, while western music highlights serene melancholy. The development of Chinese music appeared the Confucianism, Buddhism, ink, law, genre, Yin and Yang, and many other aesthetics, but they in general are melt by Confucianism and Buddhism two 
aesthetic thought. Aesthetic thoughts of Confucius thought, simple beauty, the beauty of simplicity, implicative beauty, is the interaction of nature and people, and argues that in the music aesthetic "harmony" to maintain the emotional attitude. The representative work of Confucian musician aesthetic thoughts, the book tells us the ideas of the work is the main content, skills is secondary, and moral accomplishment is the first. In the contemporary music teaching, it is especially important to have a certain artistic accomplishment. Taoist music esthetics thought mix together with China's music culture from the date of birth. Its core is natural and peaceful, desiring to reach the state of "great music sound". Taoism advocates quietism, interests focusing on landscape beauty, and advocates the unity of nature and people, often with the help of nature from my view. As we know, in terms of the traditional spirit of Chinese culture, life is the ontology, and breed is its nourishing spring never drying up. And pursue life beyond, experience life, understand the current status, and get life deep meaning of enlightenment, often become the Chinese, especially for generations of Chinese intellectuals the ultimate meaning of life.

\section{Different music aesthetic artistic conceptions of Chinese and western}

China music has a make track for soul music which sounds like strike the effect of component. It can permeate the senses, and into the heart, play nerve, and let a person can't help it, enjoy it. Western music is with the true purpose or reason, imitate the nature calmly, and give a person the sense of reality, consciousness or fanatical. It gives a person the sense of reality, emotional real, smooth, strong emotional expression. Western music wins with the intensity, while the Chinese music wins with depth. From the sound, western music pursues sound thick, plump and stereo feeling, and the pursuit of the power of the heart, on the texture of the music. It usually uses the main mode of the structure, pursues melody crisscrossed network spread of stereo effect; On the sound value instrument timbre penetration and harmony, make the music sound more thick; On the instruments and the band, with a large symphony, sonata, concerto, etc., it is always in the ensemble to strength in the ensemble to express special emotional needs.

\section{THE COMPARISON OF THOUGHT BETWEEN CHINESE AND WESTERN MUSIC AESTHETICS}

\section{A. The comparison of Chinese and western music in the pursuit}

China has five thousand years of civilization; the Confucian thought affects deeply, and it has affected the creation of music to a great extent. This leads that the highest pursuit of Chinese music is a kind of music and fusion between heaven and earth.

They think the music aesthetic pursuit should be all natural. But the whole western in terms of aesthetic pursuit mainly is influenced by ancient Greek classical music. Its purpose is in the aesthetic pursuit of music we should focus on the compatibility and conflict between subject and object. The Chinese speaks mainly middle and western main image.
Creative music in China is mainly hidden and not leak, while western music aesthetic focuses on pursuit of a comfortable emotional expression. Therefore, Chinese and western music have very big difference in terms of aesthetic pursuit. While listening to Chinese music, it does not require every listener to be able to read music, able to read Chinese works of the kernel, but you can penetrate his own life experience from the work.

\section{B. Comparison of development and inheritance between Chinese and western music}

In the process of the formation and development of the Chinese traditional music aesthetic thoughts, the mainstream is the Confucian's thought of music. Although midway some thought different from aesthetic thought appears. But eventually, it didn't form a trend. But western music esthetics thought also has experienced a long period of development; its development course is early slow, later period quick. The reason of rapid development lies in the western music esthetics thought to innovation. It does not have a constant mainstream views and the dominant idea. The development of the theory of every kind of music is based on slam the door in the past, on the basis of the traditional music esthetics thought for previous works adhering to the attitude of criticism and suspicion. From the quantitative relationship between aesthetic auditory sense of music creation and research, putting forward the idea of the most famous music is the opposite factors and factors of harmonious and unified, the heteropoly leads to unity, the unharmonious to coordination."

\section{The comparison of thought depth between Chinese and western music}

In this " Oriented to life" cultural background, Chinese music blend in rational perceptual, and sensuous pleasure makes public individual character, the soul of the music down to foreign life in the physical world, from the flow of the music and cheerful temperament, to extend their life in the empty spirit between heaven and earth, self, all things, in the wonderful enlightenment psychosomatic, ecstasy, then return true.

Therefore, it became the Chinese traditional music aesthetic experience of the main form of the most meaningful, arriving in the heart of all Chinese music beauty: "artistic conception". In western literature they pay more attention to "sense", which is the combination of emotion and reason, emotional expression to drive the thoughts and ideas. It in turn with the understanding of the thoughts and ideas express in this kind of idea and thought under the restriction of the feelings of anger. "Reasonable" is usually known as the "reproduction" of basic elements, also is to reproduce the real emotion, to express ideas in real life. It is more about the imitation and the similar nature of reality, such as Aristotle insist on in accordance with the "inevitable law" or "natural law" to create, apparently not in accordance with the main body emotion, however, the possibility of in accordance with the law of reality. And as Horace advocates "jewels" and also emphasizes works to imitate and regular follow reality. Obviously, the western theory of "reasonable" 
and said China's "artistic conception", one attaches importance to works with the main body of modern system, and the other one attaches importance to the work relations with the external reality.

\section{FUTURE COMPARISON STUDY BETWEEN CHINESE AND WESTERN MUSIC AESTHETICS}

\section{A. Object in itself to study independently}

An aesthetics history mainly is the history of the generation and development and transition of aesthetic category aesthetic proposition. Music aesthetics is the same aesthetic proposition music aesthetic categories, history of the formation, development, transformation. An era of aesthetic consciousness, on the one hand, scattered into the surface of this era now a lot of literary works of art; On the other hand, and more focus on the surface in this era of aesthetic theory works now. Therefore, the aesthetic consciousness of a nation's history, perform for the two series: one is the image of the series; the other one is the category of the series. Research of image series is each art history; the research category series is aesthetics. Aesthetics is the study of each era characterized by the theory of aesthetic consciousness of the form. Each the aesthetic consciousness of the Times, always focuses on the surface of each era now some great thinkers of aesthetic theory, and the great thinkers of the aesthetic theory are often embodied in a number of aesthetic category and aesthetic proposition. Aesthetic category and aesthetic proposition is an era of aesthetic consciousness of the theory of crystallization.

\section{B. Referring to each other as a comparative study}

The comparison study is the beginning of Chinese modern academic study. Modern scholars know that. They once said: "the word of Chinese and western, boom at the same time, and fail at the same time failure. They push each other developing.

The view of" the second "research" in Chinese and western music aesthetics research is focus on comparative study, namely with the perspective of other aesthetic theory as a reference for comparative studies. It embodies in two aspects: one is taking the perspective of western music aesthetics as a reference to study the Chinese music aesthetics; the second is taking the perspective of Chinese music aesthetics as a reference to study the western music aesthetics.

This premise of comparative study is based on the other side of the perspective of aesthetic issues as a reference, namely in the study of Chinese music aesthetic angle of view,
China's problem of western music aesthetics perspective in the study of music aesthetics in the western music aesthetics.

\section{CONCLUSIONS}

When discussing the comparison of the music esthetics thought characteristic and the cultural spirit of Chinese and western comparison, this article attempts to find the difference and cultural values from the western music aesthetic theory. The Chinese and western music aesthetics are based on Chinese and western culture. The author summarizes the difference of Chinese and western musical thought refined with several words. "Harmony" and "artistic conception" and so on in Chinese music aesthetics, condense the essence of Chinese traditional music, and also reflect Confucianism and Taoism thought celebrating music culture "good music", "joyful" within the embodiment of the idea the Chinese for thousands of years.

Human aesthetic values have its commonality, but in the long history, different cultures form very different aesthetic habits. When compare western music aesthetic theory, we use the same words to sum up the Chinese music aesthetics. There are also theories with China's point of view, but the formation and development of the view, there are a lot of advantages we can draw lessons from. So in Chinese and western music aesthetics characteristics and comparative study of cultural spirit, we can summarize and scan Chinese traditional music aesthetic and cultural spirit.

\section{Reference}

[1] Xiao Xinyang. the comparative study of music aesthetic thoughts and culture of Chinese and western [J]. Journal of Yellow River, 2010, 11:39-40.

[2] Yuan ChunLei. Comparative study of Chinese and western music aesthetics [J]. Journal of Yellow River, 2012,01:101

[3] Han Zhongen. A exists, different expression, several problems in the Chinese and western music aesthetics [J]. Journal of shenzhen university (humanities and social science edition), 2012, 2012:14 -21.

[4] Long Hui. Chinese and western music aesthetics research triple perspective [J]. Journal of jianghan university (social science edition), 2006, 106:106-109.

[5] Wang Guan. Comparative study of Chinese and western music aesthetics [J]. China's school education, and: 1.

[6] Han Yu. The similarities and differences between Chinese and western music aesthetics [J]. Journal of the science and technology, 2014, 21:186. 